\title{
Stentolith of common bile duct - a case report
}

\author{
Sumita Pradhan, Bishnu Kandel, Paleswan Joshi Lakhey \\ Department of Surgery, Tribhuvan University Teaching Hospital \\ Correspondence: Dr Sumita Pradhan
}

Email: sumiepradhan@gmail.com

\begin{abstract}
Foreign bodies acting as a nidus for stone formation are commonly reported but there are only few case reports on forgotten biliary stents. ERCP and stone removal with or without stenting for common bile duct stones are getting quite popular and there have been instances where the stent has been forgotten either by the patient or the physician.
\end{abstract}

Keywords: Common bile duct, ERCP, forgotten stent.

\section{Introduction}

Endoscopic retrograde cholangiography (ERCP) and stone removal with or without stent placemen is the gold standard treatment for choledocholithiasis. ${ }^{1}$ Most physicians remove the common bile duct (CBD) stent at around 6 weeks of its placement. If stent removal is missed, it may lead to complications. ${ }^{2}$ Very few cases have been reported of forgotten stent complications like infection, bile duct injury, perforation, stentolith and stent migration with intestinal perforation. ${ }^{3}$ Stentolith is one of the rare complications that can cause biliary obstruction and cholangitis.

We report a case of 39-year old gentleman, who underwent endoscopic clearance of common bile duct with papillotomy and biliary stenting 3 years back for choledocholithiasis. The patient was lost to follow up. He presented after two years to our hospital with severe abdominal pain associated with nausea and vomiting. There was no recent history of cholangitis or jaundice over the past two years. On abdominal ultrasound there was stent in situ in the CBD with cholelithiasis. The liver function tests were within normal limits. Endoscopic stent removal was tried but was not successful. Magnetic resonance cholangiopancreatography (MRCP) was done which revealed a large stone with stent in situ (Figure 1). In view of impacted large stone in the $\mathrm{CBD}$, the patient was planned for open CBD exploration. Intraoperatively stent was found to be impacted with calculi at the tip. The stent along with calculi were removed (Figure 2). Check choledochoscopy was done to confirm the clearance of the CBD and a cholecystectomy was done. A T- tube cholangiogram performed one week later revealed no residual calculi. The patient was doing well at 6 months of follow up.

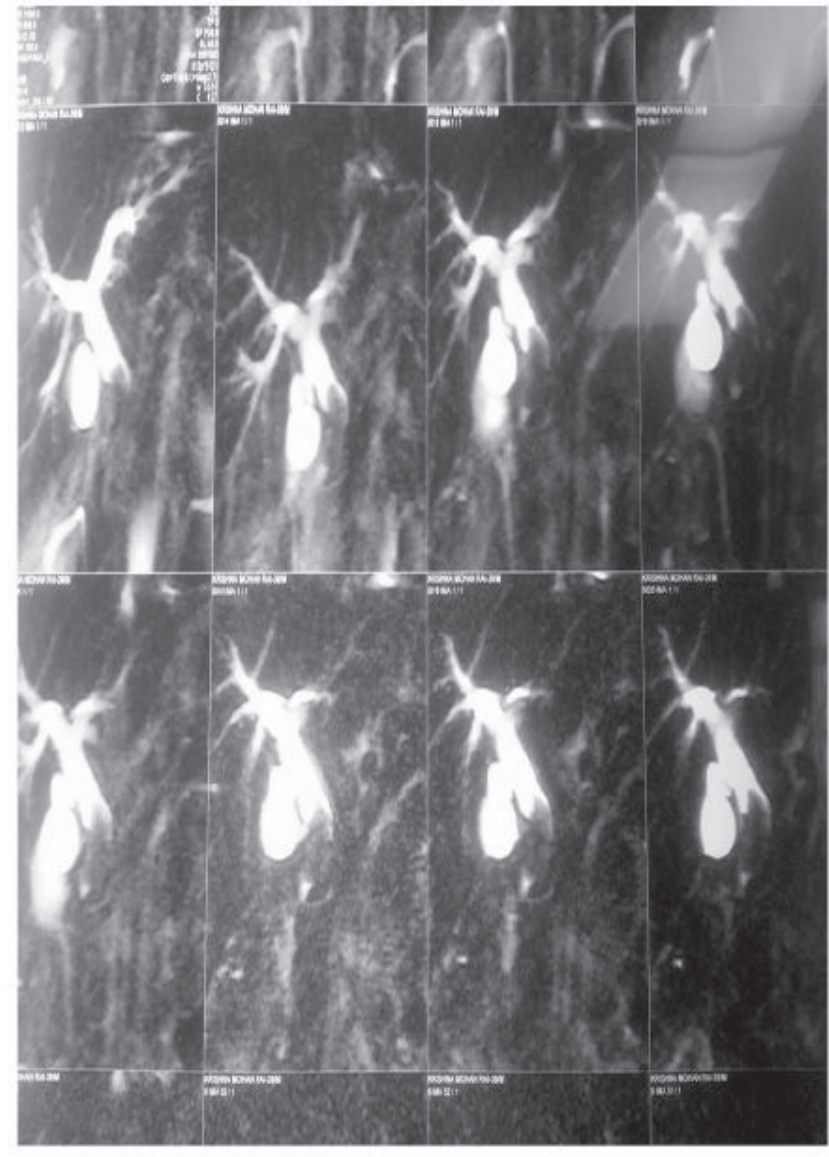

Figure 1: MRCP with meniscus sign 


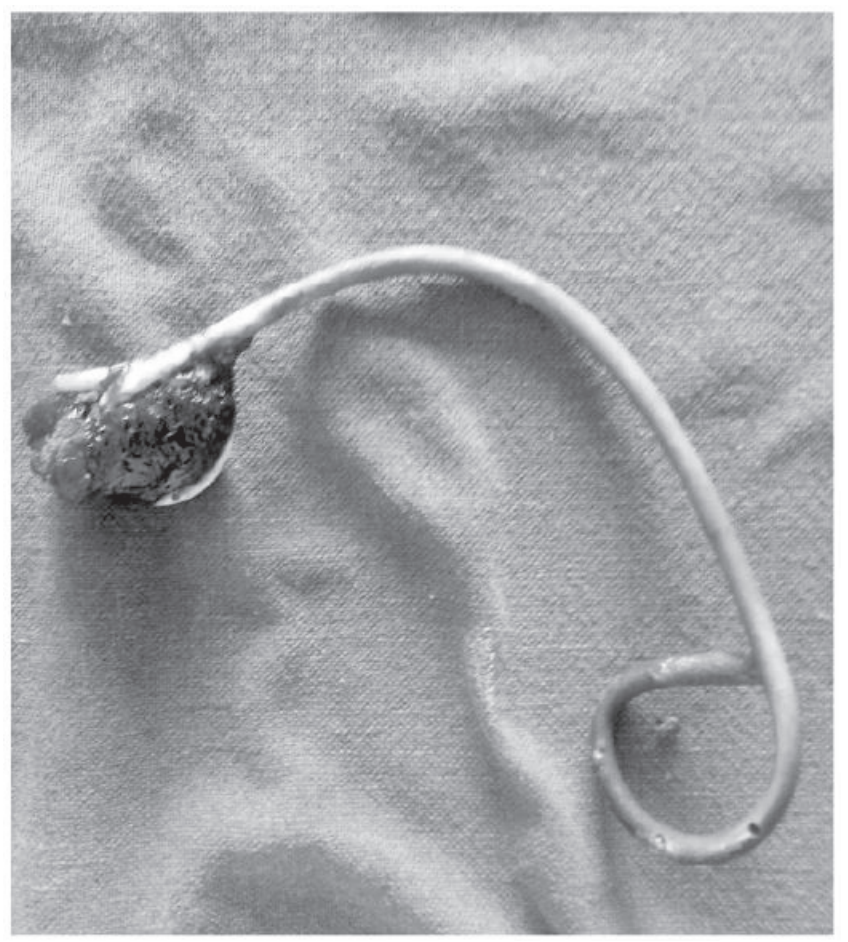

Figure 2: Stentolith after removal from common bile duct.

\section{Discussion}

With the advent of ERCP techniques, treatment of CBD stones has become much easier. Patients that require biliary stenting must be counseled for either stent removal or stent exchange. However some might forget as their symptoms improve just like in our case and do not seek consultation unless they develop symptoms later. There are numerous reports of a foreign body acting as a nidus for stone formation within the biliary system. ${ }^{4}$ Plastic stents if kept for a prolonged period promote bacterial proliferation, and release of bacterial beta-glucuronidase, which results in the precipitation of calcium bilirubinate. ${ }^{5}$

Systematic literature search of the PubMed using the search term "forgotten biliary stent" revealed only four published case reports until August 2014. It has been managed by CBD exploration and choledochoduodenostomy as well as by laparoscopic removal.,

In today's world where medico legal litigations are quite high, it rests upon the treating doctor to educate patient properly and stress on the need for follow up in order to avoid complications like stentolith. Importance of maintaining "stent registry system" for all patients who undergo ERCP and stenting has been advocated for obvious reasons. ${ }^{3}$

\section{Conclusion}

Endoscopic placement of stent is a simple and a common procedure, but after insertion of any endoprosthesis, all patients should be informed and the possibility of complications related to long-term endoprosthesis placement should be well explained.

\section{References}

1. Culnan DM, Cicuto BJ, Singh H, Cherry RA. Percutaneous retrieval of a biliary stent after migration and ileal perforation. World J Emerg Surg.2009 Jan;4:6. doi:10.1186/1749-7922-4-6. https://doi. org/10.1186/1749-7922-4-6

2. Patel TJ, Rajput S, Patel K S, Haribhakti SP. A forgotten biliary stent for 17 years: Presented with perforated gallbladder and stentolith.J Dig Endosc.2014:5(1); 223. https://doi.org/10.4103/0976-5042.141931

3. Bansal VK, Misra MC, Bhowate P, Kumar S. Laparoscopic management of common bile duct "Stentolith". Trop Gastroenterol.2009 AprJun;30(2):95-6. PMid:19760992

4. Cipolletta L, Bianco MA, Rotondano G, Prisco A, Catalano M, Gatto A, et al. Endoscopic retrieval of a surgical gauze from the common bile duct. Ital J Gastroenterol Hepatol.1997 Feb;29(1):58-61. PMid:9265581

5. Yu JL, Andersson R, Wang LQ, Ljungh A, Bengmark S. Experimental foreign-body infection in the biliary tract in rats. Scand J Gastroenterol. 1995 May; 30:478-83.PMid:7638576. https://doi. org/10.3109/00365529509093311

6. Gupta V, Chandra A, Noushif M, Singh SK. Gi $\neg$ ant stentolith: complication of a forgotten biliary stent. Endoscopy.2013;45 Suppl 2 UCTN:E126. 